\title{
Multi-Level Marketing (MLM) Perspektif Ekonomi Islam
}

\author{
Ahmad Mardalis \& Nur Hasanah \\ Sekolah Pascasarjana Universitas Muhammadiyah Surakarta \\ E-mail: nurhasanah@gmail.com
}

\begin{abstract}
ABSTRAK
Diskursus mengenai praktik Multi-Level Marketing selalu hangat diperbincangkan. Hal ini sebabkan karena terdapat pro-kontra terkait kebolehan praktik ini dalam transaksi barang maupun jasa. Salah satu keuntungan dari produk ini adalah memungkinkan minimalisir biaya distribusi produk yang dipasarkan sangat minim bahkan sampai ke titik nol. Sehingga tidak diperlukan biaya distribusi. Dengan melakukan telaah atas literatur yang relevan, penulis berkesimpulan bahwa dalam menyikapi bisnis MLM, perlu adanya wawasan dan pemahaman yang utuh dan mendalam (kaffah). Sebab segala bentuk bisnis, termasuk MLM, pada dasarnya adalah boleh jika tidak ada hal-hal yang dilarang oleh syariah. Namun jika terdapat unsur-unsur yang diharamkan, maka bisnis tersebut haram hukumnya.
\end{abstract}

Kata Kunci: Multi-Level Marketing, Ekonomi Islam, Syariah Islam.

\section{Pendahuluan}

Multi Level marketing (MLM) secara etimologi berarti pemasaran yang berjenjang banyak (Harefa, 1999: 4). MLM merupakan salah satu dari berbagai cara yang dapat dipilih oleh perusahaan untuk memasarkan produknya. Dalam MLM pelanggan diberdayakan untuk melaksanakan tugas pemasaran atau pendistribusian secara mandiri tanpa campur tangan langsung perusahaan. Imbalannya dalam bentuk potongan harga, komisi, atau insentif yang ditetapkan oleh perusahaan produsen secara berjenjang sesuai dengan jumlah nilai penjualan (biasanya disebut volume point atau bussiness point) yang diberitahukan kepada distributor independen sejak mereka mendaftar sebagai anggota (Hanefa, 1999: 4). Dalam kata lain Multi Level Marketing dapat dikatakan sebagai pemasaran yang dilakukan melalui banyak level atau tingkatan, yang biasanya dikenal dengan 
istilah up line (tingkat atas) dan down line (tingkat bawah). Upline (promotor) adalah anggota yang sudah menjadi anggota terlebih dahulu, sedangkan bawahan (downline) adalah anggota baru yang mendaftar atau direkrut oleh promotor. Jenjang keanggotaan ini bisa saja berubah-ubah, sesuai dengan syarat pembayaran atau pembelian tertentu.

MLM ini bisa juga disebut sebagai network marketing. Disebut demikian karena anggota kelompok tersebut semakin banyak sehingga membentuk sebuah jaringan kerja (network) yang merupakan suatu sistem pemasaran dengan menggunakan jaringan kerja banyak orang yang melakukan pemasaran.

Sebagian orang ada juga yang menyebut MLM sebagai bisnis penjualan langsung atau direct selling. Pendapat ini berdasarkan pelaksanaan penjualan MLM yang dilakukan secara langsung oleh juru jual kepada konsumen. Aktifitas penjualan tersebut dilakukan oleh seorang penjual disertai penjelasan, presentase dan demo produk. Di Indonesia saat ini penjualan langsung atau direct selling baik yang single level maupun multi level bergabung dalam suatu asosiasi yaitu Asosiasi Penjualan Langsung Indonesia (APLI). Organisasi ini merupakan anggota KADIN, bagian dari World Federation Direct selling Association (WFDSA) (Dewi dkk,: 144).

\section{Sejarah Multi Level Marketing}

Sebelum MLM, sudah dikenal istilah dirrect selling. Direct selling pertama kali muncul pada tahun 1886 dengan beroperasinya The California Perfume Company di New York yang didirikan oleh Dave Mc Connel. Mc Connel ini mempekerjakan Mrs. Albee sebagai California Perfume lady untuk menjual langsung kepada calon pembeli dari rumah ke rumah. Pada tahun 1939, perusahaan ini kemudian berganti nama menjadi Avon. Mrs. Albee sendiri dianggap sebagai pioneer metode penjualan direct selling.

Pada tahun 1934 muncul perusahaan Nutrilite di California dengan metode penjualan baru yaitu memberi komisi tambahan pada distributor indipenden yang berhasil merekrut, melatih dan membantu anggota baru untuk ikut menjual produk. Metode baru ini memungkinkan seorang distributor terus merekrut anggota baru dengan kedalaman dan keluasan yang tidak terbatas. Berikutnya 
menyusul perusahaan Shaklee pada tahun 1956 dan di tahun 1959 berdiri Amway dengan metode penjualan yang sama dan kemudian dikenal dengan metode penjualan Multi Level Marketing (MLM).

MLM memberikan kesempatan dan menawarkan kemudahan kepada setiap pelanggan dengan cara yang sederhana untuk menambah penghasilan mereka. MLM memungkinkan setiap orang untuk berbisnis secara unik dan inovatif. Produk dan jasa mereka tawarkan tanpa mengeluarkan biaya iklan yang mahal dan tanpa harus bersaing di toko-toko pengecer. Dengan cara yang unik dan inovatif inilah, MLM telah menjadi metode penjualan yang sukses selama kurang lebih dari lima (5) dasawarsa terakhir (Fuad, 2009: 55).

\section{Konsep Dasar Multi Level Marketing}

MLM memungkinkan biaya distribusi dari produk yang dipasarkan sangat minim bahkan sampai ke titik nol. Sehingga tidak diperlukan biaya distribusi. MLM juga menghilangkan biaya promosi dari barang yang hendak dijual karena distribusi dan promosi ditangani langsung oleh distributor dengan sistem berjenjang. Dalam MLM terdapat unsur jasa. Artinya seorang distributor menjualkan barang yang bukan miliknya. Ia akan mendapatkan upah dari prosentase harga barang. Jika dapat menjual sesuai target dia akan mendapat bonus yang ditetapkan perusahaan.

Mekanisme operasional pada MLM ini adalah seorang distributor dapat mengajak orang lain untuk ikut juga sebagai distributor. Kemudian orang lain itu dapat mengajak pula orang lain lagi untuk ikut bergabung. Begitu seterusnya, semua yang diajak dan ikut merupakan suatu kelompok distributor yang bebas mengajak orang lain lagi sampai level yang tanpa batas. Inilah salah satu perbedaan MLM dengan pendistribusian secara konvensional yang bersifat single level. Kemunculan trend strategi pemasaran produk melalui sistem MLM di dunia bisnis modern sangat menguntungkan banyak pihak. Seperti pengusaha dan para distributor. 


\section{Kontroversi Multi Level Marketing}

Kerancuan antara MLM dengan sistem money game seringkali ditemukan. MLM pada hakikatnya adalah bisnis yang berdasar pada sistem pendistribusian barang. Bonus didapatkan dari total omzet penjualan barang yang didistribusikan melalui jaringannya. Hal ini berbeda dengan sistem money game, dimana pendapatan bonus didapat dari perekrutan, bukan dari omzet penjualan barang. Kesulitan membedakan MLM dengan permainan uang terjadi karena bonus yang diterima berupa gabungan dengan komposisi tertentu antara bonus perekrutan dan komisi omzet penjualan. Sistem permainan uang cenderung menggunakan skema piramida (atau skema Ponzi) dan orang yang terakhir bergabung akan kesulitan mengembangkan bisnisnya. Dalam MLM, walaupun telah memiliki banyak bawahan, tetapi tanpa omzet, bonus tidak akan diperoleh.

Tabel 1. Perbedaan praktek MLM dengan money game

\begin{tabular}{|c|c|}
\hline MLM & MONEY GAME \\
\hline $\begin{array}{l}\text { 1. Biaya pendaftaran tidak mahal } \\
\text { dan setara dengan nilai barang } \\
\text { 2. Ada produk yang dipasarkan } \\
\text { 3. Semua anggota punya peluang } \\
\text { yang sama } \\
\text { 4. Keberhasilan berdasarkan hasil } \\
\text { penjualan dan perekrutan } \\
\text { 5. Perlu kerja keras }\end{array}$ & $\begin{array}{l}\text { 1. Biaya pendaftaran sangat mahal } \\
\text { 2. Tidak ada barang yang dijual } \\
\text { (sekedar kedok) } \\
\text { 3. Yang mendaftar awal lebih } \\
\text { untung } \\
\text { 4. Keberhasilan ditentukan jumlah } \\
\text { uang yang disetor dan orang } \\
\text { yang direkrut } \\
\text { 5. Tidak perlu kerja keras (bagi up } \\
\text { line). }\end{array}$ \\
\hline
\end{tabular}

Sumber: disadur dari berbagai sumber

Biaya keanggotaan bawahan secara virtual telah dibagikan menjadi komisi promotor. Harga barang menjadi terlalu mahal untuk menutupi pembayaran komisi para promotor. Dalam jangka panjang, hal ini membuat komisi menjadi tidak seimbang. Karena komisi melebihi harga barang dikurangi harga produksi. Konsumen di tingkat tertinggi mendapatkan harga termurah atau bahkan mendapatkan keuntungan. Sedangkan konsumen yang baru bergabung mendapatkan kerugian secara tidak langsung karena mendapatkan harga termahal dan tidak mendapatkan komisi. Akhirnya, anggota baru tersebut terangsang untuk mencari konsumen baru agar mendapat komisi yang bisa menutupi kerugian 
virtual yang ditanggungnya. Pelanggaran bisa pula terjadi bila perusahaan penyedia sistem MLM menjanjikan sesuatu berlebihan yang tidak mungkin bisa dicapai konsumen.

\section{Tinjauan Hukum Islam Mengenai MLM}

Dari aspek hukum terdapat perbedaan pendapat mengenai halal atau tidaknya MLM ini. Padahal, tawaran untuk bergabung dengan bisnis ini semakin gencar saja. Setidaknya, ada tiga pendapat menurut para ulama mengenai bisnis MLM ini:

1. Pendapat yang mengharamkan, menganggap MLM ini tidak sesuai dengan syariat Islam. Karena anggota MLM menjual produk yang bukan miliknya, melainkan milik perusahaan suplier atau perusahaan produk. Up line menjual kepada down line dan seterusnya, padahal barangnya sendiri tidak mereka miliki dan tidak mereka beli. Selain pendapat itu, pada sistem MLM terdapat dua akad, yaitu akad jual beli sekaligus akad makelar atau perekrutan (simsarah). Dalam hadist disebutkan: "Tidak halal menjual sesuatu dengan syarat memberikan hutangan, dua syarat dalam satu transaksi, keuntungan menjual sesuatu yang belum engkau jamin, serta menjual sesuatu yang bukan milikmu." (HR. Abu Daud)

2. Pendapat kedua, MLM halal apabila tidak bertentangan dengan syariah. Ada dua point besar yang perlu diperhatikan, yaitu produknya dan sistemnya. Mengenai anggapan kedua ini, akan dibahas lebih dalam pada pembahasan selanjutnya

3. Pendapat ketiga antara halal dan haram (syubhat), karena melihat perbedaan pendapat dan terlebih melihat dampak negatif yang terjadi pada beberapa kasus. MLM dapat memberikan obsesi yang berlebihan terhadap harta dan seringkali membuat membernya lupa daratan (Gozali, 2005).

Bisnis dalam syari'ah Islam pada dasarnya termasuk kategori muamalat yang hukum asalnya adalah boleh berdasarkan kaidah Fiqh " Al-Ashlu fil muamalah alibahah hatta yadullad dalilu 'ala tahrimiha" -pada dasarnya segala hukum dalam muamalah adalah boleh, kecuali ada dalil yang melarangnya). 
Islam memahami bahwa perkembangan budaya bisnis berjalan begitu cepat dan dinamis. Berdasarkan kaedah fikih di atas, maka terlihat bahwa Islam memberikan jalan bagi manusia untuk melakukan berbagai improvisasi dan inovasi melalui sistem, teknik dan mediasi dalam melakukan perdagangan.

Namun, Islam mempunyai prinsip-prinsip tentang pengembangan sistem bisnis yaitu harus terbebas dari unsur bahaya (dharar), ketidakjelasan (jahalah) dan merugikan salah satu pihak (zhulm). Sistem pemberian bonus harus adil, tidak menzalimi dan tidak hanya menguntungkan orang yang di atas saja.

Dalam kajian fiqh kontemporer bisnis MLM ini dapat ditinjau dari dua aspek, yaitu produk barang atau jasa yang dijual dan cara atau sistem penjualannya (selling marketing). MLM yang menggunakan strategi pemasaran secara bertingkat (levelisasi) mengandung unsur-unsur positif, asalkan diisi dengan nilainilai Islam dan sistemnya disesuaikan dengan syari’ah Islam. Bila demikian, MLM dipandang memiliki unsur-unsur silaturrahmi, dakwah dan tarbiyah.

Menurut Muhammad Hidayat, Dewan Syari'ah MUI Pusat, metode semacam ini pernah digunakan Rasulullah dalam melakukan dakwah Islamiyah pada awalawal Islam. Dakwah Islam pada saat itu dilakukan melalui teori gethok tular (mulut ke mulut) dari sahabat satu ke sahabat lainnya. Sehingga pada suatu ketika Islam dapat di terima oleh masyarakat kebanyakan (Tarigan, 2002: 30).

Mengenai produk atau barang yang dijual apakah halal atau haram tergantung kandungannya, apakah terdapat sesuatu yang diharamkan Allah seperti unsur babi, khamr, bangkai atau darah. Begitu pula dengan jasa yang dijual apakah mengandung unsur kemaksiatan seperti praktik perzinaan, perjudian atau perdagangan anak dsb, dan ini semua bisa kita rujuk pada serifikasi Halal dari LPPOM MUI.

Kegiatan samsarah dalam bentuk distributor, agen, member atau mitra niaga dalam fikih Islam termasuk dalam akad ijarah. Yaitu suatu transaksi memanfaatkan jasa orang lain dengan imbalan, insentif atau bonus (ujrah). Pada dasarnya para ulama seperti Ibnu Abbas, Imam Bukhari, Ibnu Sirin, Atha dan Ibrahim memandang boleh jasa ini (Tarigan, 2002: 30). Namun untuk sahnya pekerjaan ini harus memenuhi beberapa syarat, sebagai berikut:

1) Adanya Perjanjian yang jelas antara kedua belah pihak 
2) Objek akad bisa diketahui manfaatnya secara nyata dan dapat diserahkan

3) Objek akad bukan hal-hal yang diharamkan dan maksiat

Distributor dan perusahaan harus jujur, ikhlas, transparan, tidak menipu dan tidak menjalankan bisnis yang haram dan syubhat (tidak jelas halal dan haramnya). Distributor dalam hal ini berhak menerima imbalan setelah berhasil memenuhi akadnya. Sedangkan pihak perusahaan yang menggunakan jasa marketing harus segera memberikan imbalan para distributor dan tidak boleh menghanguskan atau menghilangkannya. Pola ini sejalan dengan firman Allah, "Maka sempurnakanlah takaran dan timbangan dan janganlah kamu kurangkan bagi manusia barang-barang takaran dan timbangannya” (QS. Al-Baqarah[2]: 233)

Dan hadis Rasulullah Saw. "Berilah para pekerja itu upahnya sebelum kering keringatnya." (H.R. Ibnu Majah). Jumlah upah atau imbalan jasa yang harus diberikan kepada makelar atau distributor adalah menurut perjanjian sesuai AlQur'an "Hai orang-orang yang beriman, penuhilah aqad-aqad itu” (QS. AlMa'idah[5]:1)

Karena bisnis MLM merupakan bagian dari perdagangan, oleh sebab itu bisnis ini juga harus memenuhi syarat dan rukun sahnya sebuah perikatan.

\section{Multi Level Marketing Syariah}

Secara realitas, kini perusahaan MLM sudah banyak tumbuh dan berkembang, baik di dalam maupun luar negeri. Bahkan di Indonesia sudah ada yang secara terang terangan menyatakan bahwa MLM tersebut sesuai syariat dan mendapatkan sertifikasi halal dari Dewan Syariah Nasional Majelis Ulama Indonesia (DSNMUI). Untuk MLM yang berdasarkan prinsip syariah ini, masih diperlukan akuntabilitas dari MUI. Ada dua aspek untuk menilai apakah bisnis MLM itu sesuai dengan syariah atau tidak yaitu, (1) Aspek produk atau jasa yang dijual, (2) Sistem dari MLM itu sendiri.

Dari aspek produk yang dijual, harus merupakan produk-produk yang halal, bermanfaat dan dapat diserah terimakan serta mempunyai harga yang jelas. MLM yang dikelola oleh seorang muslim, jika objeknya tidak memenuhi diatas, hukumnya tidak sah. Adapun dari aspek sistem, pada dasarnya MLM yang 
berbasis syariah tidak jauh berbeda dengan MLM konvensional. Yang membedakan adalah bentuk usaha atau jasa harus memenuhi hal-hal sebagai berikut: pertama, produk yang dipasarkan harus halal, baik dan menjauhi syubhat. Kedua, sistem akadnya harus memenuhi kaedah dan rukun jual beli sebagaimana yang terdapat dalam hukum Islam. Ketiga, Operasional, kebijakan, budaya oraganisasi, maupun sistem akuntansinya harus sesuai syari'ah. Keempat, tidak ada mark up harga produk yang berlebihan, sehingga anggota terzalimi dengan harga yang amat mahal, tidak sepadan dengan kualitas dan manfaat yang diperoleh. Kelima, dalam struktur organisasinya, perlu ada Dewan Pengawas Syari'ah (DPS) yang terdiri dari para ulama yang memahami permasalahannya. Selanjutnya, formula insensif harus adil, tidak menzalimi down line dan tidak menempatkan up line hanya menerima pasif income tanpa bekerja, up line tidak boleh menerima income dari hasil jerih payah down linenya. Pembagian bonus harus mencerminkan usaha masing-masing anggota. Tidak ada eksploitasi dalam aturan pembagian bonus antara orang yang awal menjadi anggota dengan yang akhir. Oleh karena itu pembagian bonus yang diberikan harus jelas angka nisbahnya sejak awal. Cara pemberian penghargaan kepada mereka yang berprestasi tidak hura-hura dan pesta pora. Produk yang dijual tidak menitik beratkan barang-barang tertier, terutama ketika ummat masih bergelut dengan pemenuhan kebutuhan primer. Disamping itu, perusahaan MLM harus berorientasi pada kemaslahatan ekonomi ummat.

\section{Kesimpulan}

MLM adalah salah satu metode penjualan produk yang belakangan ini banyak dipraktekkan karena dianggap efektif. Dalam menyikapi bisnis MLM, perlu adanya wawasan dan pemahaman yang baik, benar dan utuh. Karena MLM termasuk dalam ilmu mikro, maka aplikasi sutau MLM dengan MLM lainnya tidak sama dalam menjalankan bisnisnya. Terutama ditinjau dari segi barang yang dijual dan bentuk transaksi yang dijalankan. Sehingga dalam menetapkan hukum pun juga berbeda antara satu MLM dengan MLM yang lain. Semua bentuk bisnis, termasuk MLM, pada dasarnya adalah boleh jika tidak ada hal-hal yang dilarang 
oleh syariah. Namun jika terdapat unsur-unsur yang diharamkan syariat, maka bisnis tersebut haram hukumnya.

Konsep ekonomi Islam dalam penjualan suatu produk menekankan kehalalan, manfaat, dan mematuhi prinsip dasar ekonomi syari'ah secara makro yang terbebas dari tujuh (7) unsur yaitu maysir (judi), aniaya (zhulm), gharar (penipuan), haram, riba (bunga), iktinaz atau ihtikar.

\section{Daftar Pustaka}

Dewi, Gemala, (Tanpa Tahun), Hukum Perikatan Islam di Indonesia, (Jakarta: Prenada Media)

Fuad, (2009), “Multilevel Marketing dalam Tinjauan Hukum Islam”, Jurnal Ekonomi dan Bisnis Islam,Vol 4, No.1

Ghozali, Ahmad, (2005), “MLM, Bagaimana Hukumnya”, Harian Republika.

Harefa, Andreas, (1999), Multi Level Marketing: Alternatif Karier dan Usaha Menyongsong Millenium Ketiga, (Jakarta : PT Gramedia Pustaka Utama).

Hidayat, Mohammad, (2003), “Analisa Teoritis Normatif Multi Level Marketing dalam perspektif Muammalah”, Makalah dalam "Forum Majelis Tarjih dan Pengembangan pemikiran Islam", Padang.

Sabiq, Sayyid, Fiqh as-Sunnah, vol.III

Tarigan, Azhari Akmal, (2002), Ekonomi dan Bank Syari'ah, FKEBI IAIN.

Bisnis Dengan Sistem MLM dalam http://www.dakwatuna.com/2006- artikel ekonomi syariah

Dewan syariah dalam MLM diambil dari http://www.e-syariah.com http://blog.esoftdream.net/index.php/2007/02/27/ "Kontroversi Mengenai MLM" http://taukhid.wordpress.com/2009/02/13. "Hukum MLM dalam pandangan Islam"

http://dokternasir.web.id/2009/03/multi-level-marketing-dalam-perspektif-fiqihislam.html

http://saabiq01.blogspot.com/2011/10. "Multi Level Marketing dalam Perspektif Islam" 